\title{
External jugular vein aneurysm: successful endovascular management of an exceedingly rare entity
}

\author{
Niraj Nirmal Pandey, Mumun Sinha, Amit Deshpande ํㅜ, Sanjeev Kumar
}

Cardiovascular Radiology and Endovascular Interventions, All India Institute of Medical Sciences, New Delhi, Delhi, India

Correspondence to Dr Sanjeev Kumar; sanjeevradio@gmail.com

Accepted 26 January 2020

\section{DESCRIPTION}

A 12-year-old girl presented with a painful, nonpulsatile swelling in the right supraclavicular fossa of 6-month duration, which increased in size on straining and coughing (figure 1A). Physical examination and auscultation confirmed the nonpulsatile nature of the swelling with absence of any thrill or bruit. A Doppler ultrasound examination (figure 1B) and a subsequent contrast-enhanced CT (figure 1C-D) confirmed the swelling to be an outpouching, measuring $3.3 \times 3 \times 2.5 \mathrm{~cm}$, arising from the posteromedial aspect of the right external jugular vein (EJV). No other venous channels were seen communicating with the lesion. The right EJV was seen to be displaced laterally and draped over the swelling. Thin septations were also seen within the lesion. No thrombus was seen.

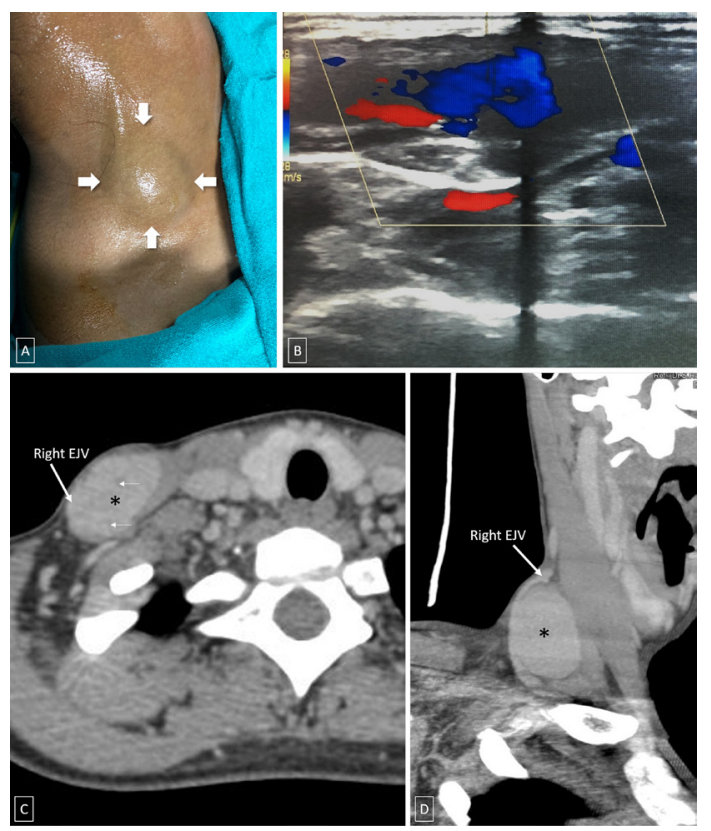

Figure 1 Clinical photograph $(A)$ reveals a $3 \times 3 \mathrm{~cm}$ swelling (delineated by arrows) in the right supraclavicular fossa. Ultrasound Doppler image (B) shows venous flow within the sac. Contrast-enhanced $\mathrm{CT}$ images in the axial (C) and oblique coronal (D) planes demonstrate an outpouching $\left({ }^{*}\right)$, measuring $3.3 \times 3 \times 2.5 \mathrm{~cm}$, arising from the posteromedial aspect of the right external jugular vein (EJV), which is seen to be displaced laterally and draping over the swelling. Thin septations (thin white arrows) are also seen within the lesion with no thrombus present.

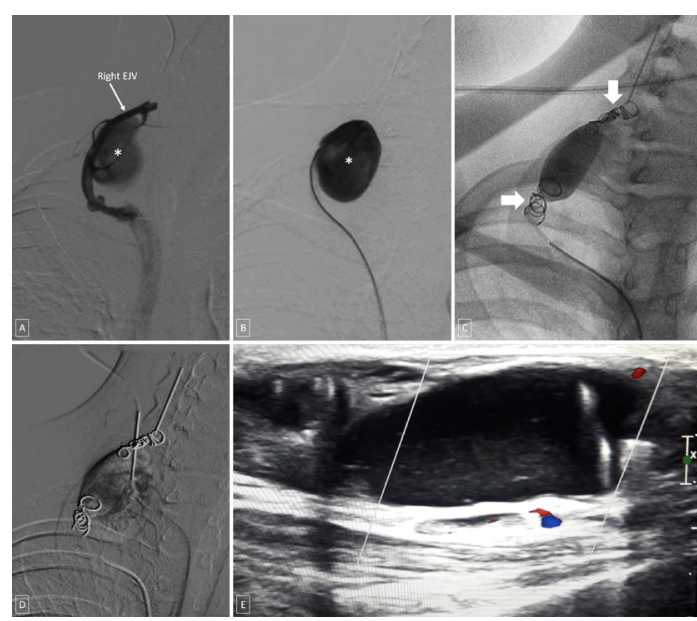

Figure 2 Diagnostic venogram (A, B) reveals a welldefined, multi-septated, saccular outpouching $\left({ }^{*}\right)$ from its posteromedial aspect with a narrow neck. (C) The right external jugular vein (EJV) embolised both proximal and distal to the neck of outpouching using multiple coils (thick arrows). (D) Percutaneous injection of foamsclerosant into the sac. Ultrasound Doppler (E) reveals complete thrombosis of the sac with no colour flow within.

In view of persistent pain and for cosmetic reasons, the patient was planned for endovascular embolisation. The right EJV was cannulated proximal to the outpouching using a butterfly cannula (22G) and diagnostic venogram performed which showed the presence of a well-defined, multiseptated, saccular outpouching from its posteromedial aspect with a narrow neck (figure $2 \mathrm{~A}-\mathrm{B}$ ). The right EJV was cannulated via a right transfemoral venous access and successfully embolised, both proximal and distal to the neck of outpouching, using multiple pushable coils (figure 2C). The sac was then punctured percutaneously, aspirated and a contrast injection done to confirm absence of any tributaries or any reflux into the right EJV. Subsequently, foam-sclerosant $(3 \mathrm{~mL}$ of $1 \%$ polidocanol mixed with air in 1:4 ratio) was injected into the sac and compressed (figure 2D). Ultrasound Doppler showed complete thrombosis of the sac (figure 2E) along with reduction in the size of the swelling at 2-week follow-up examination.

EJV aneurysm is an exceedingly rare entity and hence their exact incidence is unknown. They typically present as a cervical mass, which shows alteration in size with position and with Valsalva 
manoeuvre. While clinical findings and ultrasound is often diagnostic, CT can help provide a roadmap for retrograde venous catheterisation of the feeding vein, demonstrate any additional feeders and delineate deeper extensions of the venous aneurysm, which might be overlooked on the ultrasound examination. Patients may present will dull pain at the site of swelling, but are mostly asymptomatic. Usually, they do not undergo significant change in size or morphology over time and hence can be followed up without intervention. Management is commonly indicated for cosmetic reasons or when complications such as thromboembolism, rupture or thrombophlebitis arise. ${ }^{1}$ While majority of the previously reported cases have been managed with surgical excision, endovascular treatment may be an

\section{Learning points}

- External jugular vein aneurysm is an exceedingly rare entity and their exact incidence is unknown. As commonly they do not undergo significant change in size or morphology, they can be followed up without intervention.

- Management is indicated for cosmetic reasons or when complications such as thromboembolism, rupture or thrombophlebitis arise.

- It can be managed by both surgical and endovascular approaches; however, no specific guidelines for the treatment of these lesions exist. attractive option as it circumvents the issues and complications of surgery such as need for anaesthesia, potential injury to surrounding structures, wound infection, haemorrhage and scar. ${ }^{2}$ However, it would be prudent to note that secondary to the scarcity of available literature, no specific guidelines for the treatment of these lesions exist.

Contributors NNP participated sufficiently in the conception of the idea development of the intellectual content, design, writing and final approval of the manuscript. MS participated sufficiently in the conception of the idea, development of the intellectual content, design, writing and final approval of the manuscript. $A D$ participated sufficiently in the conception of the idea, development of the intellectual content, design, writing and final approval of the manuscript. SK participated sufficiently in the conception of the idea, development of the intellectual content, design, writing and final approval of the manuscript.

Funding The authors have not declared a specific grant for this research from any funding agency in the public, commercial or not-for-profit sectors.

Competing interests None declared.

Patient consent for publication Parental/guardian consent obtained.

Provenance and peer review Not commissioned; externally peer reviewed.

\section{ORCID iD}

Amit Deshpande http://orcid.org/0000-0001-7871-5688

\section{REFERENCES}

1 Calligaro KD, Ahmad S, Dandora R, et al. Venous aneurysms: surgical indications and review of the literature. Surgery 1995;117:1-6.

2 Rajadurai A, Abdul Aziz A, Mat Daud NA, et al. Embolisation of external jugular vein aneurysm: a case report. MJMS 2017;24:107-12.

Copyright 2020 BMJ Publishing Group. All rights reserved. For permission to reuse any of this content visit https://www.bmj.com/company/products-services/rights-and-licensing/permissions/

BMJ Case Report Fellows may re-use this article for personal use and teaching without any further permission.

Become a Fellow of BMJ Case Reports today and you can:

- Submit as many cases as you like

- Enjoy fast sympathetic peer review and rapid publication of accepted articles

- Access all the published articles

- Re-use any of the published material for personal use and teaching without further permission

\section{Customer Service}

If you have any further queries about your subscription, please contact our customer services team on +44 (0) 2071111105 or via email at support@bmj.com.

Visit casereports.bmj.com for more articles like this and to become a Fellow 